\title{
Küçük Otel İşletmelerinde, Yöneticilerin Pazarlama Karmasına Yönelik Tutumları: Bir Uygulama
}

\author{
DOI: 10.26466/opus.731669
}

*

\author{
Kürşad Sayın* - Abdullah Karaman** \\ * Öğr.Gör.Dr., Selçuk Ünivesitesi, Silifke Taşucu MYO, Mersin/Türkiye \\ E-Posta: kursadsyn@selcuk.edu.tr \\ ORCID: 0000-0003-0988-5186 \\ ** Prof.Dr., Selçuk Üniversitesi, Turizm Fakültesi, Konya/Türkiye \\ E-Posta: krmnab4225@gmail.com \\ ORCID: 0000-0001-7934-0451
}

\begin{abstract}
Öz
Pazarlama karması bir işletmenin pazarlama hedeflerine ulaşmak, ürünü ve markasını pazarda tanıtmak için kullandığı araçlar veya uygulamalardır. Pazarlama karmasının tüm unsurları birbirini etkiler ve yöneticiler pazarlama karması unsurların doğru olarak ele alabildikleri oranda başarı kazanabilirler. Küçük otel işletmeleri günümüzde destinasyonların turizm talebini karşılayabilmelerinde etkilidir. Konuyla ilgili yapılan araştırmalarda, çalışmaların çoğunun büyük oteller üzerine yapıldı̆̆g sonucuna ulaşılmıştır. Bu nedenle çalışma önem arz etmektedir. Çalışmanın amacını küçük otel işletmelerinde yöneticilerin pazarlama karması bileşenlerine yönelik önem algılarının hem üretici ( $7 P$ ) hem de tüketici (7C) odaklı olarak tespit edilmesi oluşturmaktadır. Çalışmada öncelikli olarak ilgili literatür araştırılmış ve anket formu oluşturulmuştur. Anketler, Mersin İli'ne bağh Silifke'deki küçük sayfiye otel yöneticilerine yüz yüze görüşme ile yaptırılmıştır. Elde edilen bulgular SPSS istatistik programı ile değerlendirilmiş, yüzde frekans analizleri tablolaştırılmış, yorumlanmış ve sonuca ulaşılmıştır. Çalışmada yöneticiler tarafindan $7 P$ bă̆lamında en önemli pazarlama karması unsuru olarak "ürün" ve "fiyat" seçeneklerinin algılandığı. "süreç" ve "fiziksel kanıtlar" unsurların öneminin yeterince algılanmadığı sonucuna ulaşılmıştır. 7C kapsamında ise "maliyet", "tüketici değeri" "erişilebilirlik" unsurlarının çok önemli unsurlar olarak algılandığı, "koordinasyon", "onaylama" ve "iletişim" unsurlarının öneminin yeterince algılanmadığı sonucuna ulaşılmıştır.
\end{abstract}

Anahtar Kelimeler: Küçük oteller, Pazarlama, Pazarlama Karması, 7C, 7P 


\title{
Attitudes of Managers Towards Marketing Mix In Small Size Hotel Businesses; An Application
}

\begin{abstract}
Marketing mix is the tools or applications that a business uses to achieve its marketing goals and promote its product and brand in the market. All the elements of the marketing mix affect each other and managers can achieve success as much as they can handle the elements of the marketing mix correctly. Small hotel enterprises today are effective in meeting the tourism demand of destinations. In researches on the subject, it was concluded that most of the studies were done on large hotels. Therefore, the study is important. The aim of the study is to determine the importance perceptions of managers for marketing mix components in small hotel businesses with a focus on both producer (7P) and consumer (7C). In the study, primarily the relevant literature was researched and a survey form was created. The surveys were conducted by face-to-face meetings with the managers of the small resort hotel in Silifke, Mersin province. The findings acquired were evaluated with the SPSS statistical program, percentage frequency analyses of which were tabulated, interpreted and the results were reached. In the study, it was concluded that "product" and "price" options were perceived as the most important marketing mix element in the context of $7 P$ and that the importance of "process" and "physical evidence" elements was not adequately perceived by managers. Under 7C, it was concluded that the" cost"," consumer value"," accessibility "elements were perceived as very important elements and that the" coordination"," approval "and" communication "elements were not adequately perceived.
\end{abstract}

Keywords: Small hotels, Marketing, Marketing Mix, 7C, 7P 


\section{Giriş}

Pazarlama, karşılanmamış ihtiyaç ve talepleri belirleyen, bu taleplerin büyüklügünü ve olası karlılıklarını tanımlayarak ölçen, organizasyonların hangi pazarlara iyi bir şekilde nasıl hizmet verileceğini saptayan, seçilmiş pazarlara hizmet verecek uygun hizmetlere, ürünlere ve programlara karar verebilen ve bir organizasyonda bulunan herkesin müşteriye hizmet etmesini isteyen bir işletme fonksiyonudur. Pazarlama karması ise "hedef pazarlarında işletme satışların belirli seviyede tutmak için kullamılan değişkenlerinin karışımı" olarak tanımlamaktadır. Bu değişkenlerin her birine pazarlama karması elemanlarını denir (Kotler, 2005, s.7). Ürün, fiyat, dağıtım ve tutundurma olarak (4P) tanımlanan pazarlama karması unsurları daha sonra hizmet pazarlaması dâhilinde değerlendirilerek, içine insan, fiziksel kanıtlar ve süreç unsurlarını da alarak 7P şeklini almıştır. Otel işletmelerinde insan unsuru hem üretici hem de tüketici konumundadır. Bu nedenle hizmet pazarlama faaliyetleri otel işletmelerinde "tüketici odakl olarak pazarlama karmasinı" (7C) ön plana çıkarmıştır (Altunışık, 2009, s.7-47).

Dünya geneline bakıldığı zaman konaklama işletmelerinin çoğunluğunu yerel ve aile işletmelerinden oluşan küçük otellerin oluşturduğu görülmektedir. Küçük oteller oda ve yatak sayısı bakımından küu̧ük olmalarına rağmen bölge ve ülke ekonomilerinde büyük öneme sahiptirler. Durgun dönemlerde bile yerel halka istikrarlı istihdam fırsatları sağlar ve yerel ekonomilerin çevre alanlara uyumunu destekler. Ayrıca, küçük oteller, turist harcamalarının yerel düzeyde yapılmasını mümkün kılar ve böylece hem yerel hem de ulusal olarak her türlü çarpanı geliştirirler. Aynı zamanda elli oda'dan az odaya sahip küçük oteller turizm destinasyonlarında turizm talebinin karşılanmasında her geçen gün artan sayıları ile de büyük rol oynamaktadır (Buhalis ve Main, 1998, s.202).

Otel işletmelerinde, pazarlama konusu hakkında yapılan çalısmaların çoğunlukla büyük işletmeler üzerinde yoğunlaştığı görülmektedir (Coviello, Winklhofer ve Hamilton, 2006, s.38). Konuyla ilgili Al-Debi ve Mustafa (2014, s.47) Ürdün'de büyük beş yıldızlı otellerin misafirlerine yönelik hizmet pazarlama karması üzerine bir çalışma yapmış ve fiziksel unsurlar ve oda unsurlarının önemli olduğu sonucuna ulaşmıştır. Sanıb vd. (2013, s.310) Malezya'daki büyük otellerde pazarlama karması unsurlarına yönelik yerel ve uluslararası misafirlerin algılarını karşılaştırmak amacıyla bir çalışma 
yapmış ve yerel misafirlerin ürünler ve hizmetlerle daha fazla ilgilendikleri, fiyatın, otel seçiminde yerel ve uluslararası misafir kararını etkilemediği sonucuna ulaşmıştır. Yine büyük otellere yönelik çalışma yapan Dutse ve Ayuba (2015, s.40-41) Nijerdaki çalışmalarında 189 otel misafiri ile 19 otel yöneticisine bir çalışma yapmışlar fakat öncelikli olarak ürün, fiyat ve promosyonların önemli olduğunu düşünerek (hizmet sektöründe çalışma yapmalarına rağmen) diğer pazarlama karması elemanlarını göz ardı etmişlerdir. Her üç fonksiyonunda misafir algıları açısından önemli olduğu sonucuna ulaşmışlardır.

Thvala ve Slabbert (2018, s.11-12) Güney Afrika'nın VAAl bölgesinde küçük otellerde konaklayan misafirlere yapmış oldukları çalışmada En önemli unsur ürün, kalite kontrolü, dağıtım, fiyat ve tanitım olduğu sonucuna ulaşmışlardır. Buddhichiwin (2015) ise Tayland'da bulunan küçük otellerde pazarlama karması üzerine bir çalışma yapmış, otel yöneticilerinin fiyat ve fiziksel kanıtlara önem verdikleri sonucuna ulaşmıştır. Yapılan bu çalışmaya göre; Yöneticiler misafirlerin büyük otellere gitmektense daha az ödeyerek daha fazla tatil yapmak isteyeceklerine inanmakta ve misafirin sürekliliği ve memnuniyeti için ise fiziksel kanıtların önemli olduğu algısına sahip olduklarını belirtmektedir.

Prapannetivuth (2015, s. 3936) ise Pattaya'da dokuz adet küçük otel yöneticisi ile yapmış olduğu görüşmede, yöneticiler için pazarlama karması unsurlarından en çok İnsanlarla iletişim, fiyatlandırma ve fiziksel kanıtların önem arz ettiği sonucuna ulaşmıştır.

Konuyla ilgili çalışmalar genellikle misafirler üzerine yapılmış, 7P ve 7C ile yönetici algılarına yönelik yapılan çok fazla çalışmaya rastlanmamıştır. Bu nedenle çalışmada küçük otel yöneticilerin pazarlama karmasına yönelik önem algılarının 7P ve 7C odaklı olarak araştırılması amaçlanmış, Silifke'de bulunan küçük sayfiye otel işletmeleri yöneticilerinin pazarlama karması bileşenlerinin önem algıları hem üretici (7p) hem de tüketici (7c) odaklı olarak tespit edilmeye çalışılmıştır. Çalışma bu nedenle önem arz etmektedir. Bunun nedenle çalışmanın ilk bölümde pazarlama ve turizm pazarlaması konusu ele alınmıştır. İkinci bölümde turizm işletmelerinde pazarlama karması konusu işlenmiştir, üçüncü bölümde ise konuyla ilgili küçük oteller üzerine yapılan bir araştırma ortaya konmuş, sonuç kısmında ise önemli sonuçlar belirtilmiştir. 


\section{Turizm Pazarlaması}

Pazarlama konusu ile ilgili yaygın kabul gören tanımlardan bir tanesi 1985 yılında AMA (Amerikan Marketing Association) tarafından yapılmıştır. Tanıma göre pazarlama "örgütsel ve kişisel amaçlara değişimi sağlayarak ulaşmak için hizmetlerin, ürünlerin ve fikirlerin geliştirilmesi, fiyatlandırlması, tutundurulmast ve dağıtımıla ilişkili planlar yapma ve uygulama sürecidir". AMA 2004 'te dünyada meydana gelen gelişmelere paralel olarak yeni bir tanım yapmıştır. Yeni tanıma göre: Pazarlama, müşterilere değer yaratmak, onlarla iletişim kurmak için gerçekleştirilen organizasyonel bir işlevdir. Pazarlama müşteri ilişkilerini organizasyonun paydaşlarının yararına olacak şekilde yönetmek için bir dizi işlemdir (Gundlach ve Wilkie, 2009, s. 259-264).

Diğer bir tanıma göre pazarlama müşteriler ile işletmelerin ortak çıarlar1 için mübadele amacıyla bir araya geldikleri "Pazar yeri" kavramından gelen bir uygulamadır (Erol, 2003, s.43). Fakat, her değişim pazarlama değildir. Pazarlamada değişimden bahsedebilmek için aşağıda belirtilen dört temel unsurun gerçekleşmesi gerekmektedir. Bunlar (Altunışık, 2009, s.747);

- Değişim sürecinde en az iki taraf ( alıcı-satıcı) bulunmalıdır

- Değişimde sürecinde tarafların birbirlerine sunabilecekleri bir değere sahip olmaları gerekir.

- Taraflar, teklifler arasında istediklerini reddetme veya seçme serbestliğine sahip olmalıdır.

- Değişim sürecinde taraflar değişime istekli olmalı ve fayda beklentisi olmalıdır

Tanımlara göre pazarlama, satıcılar ile alıcılar arasında oluşan bir değişim (mübadele) sürecidir. Oluşan bu süreç dahilinde pazarlama unsurlar1nın amacl; tüketicilerin ihtiyaç ve taleplerine uygun hizmet ve mal'ların, talep edilen zaman ve yerde, uygun fiyatla nihai tüketicilere ulaştırılmasıdır. Diğer bir ifadeyle, süreçteki temel amaç, tüketicilere değer yaratma yoluyla onların beğenisini kazanmak ve müşteri tatmini sağlamak için değişimin gerçekleşmesine yardımcı olmaktır. Sonuç olarak pazarlamayla ilgili şu değerlendirmeler yapılabilir.

- Pazarlama bir yönetim sürecidir.

- Pazarlama insanların ihtiyaçlarının giderilmesiyle ilgili bir faaliyettir.

- Pazarlama birçok faaliyet ve eylemler bütünüdür. 
- Pazarlama, aynı zamanda fikir pazarlanması amaciyla da kullanılabilir.

- Pazarlamanın görevi sadece satıss yapmak değil, aynı zamanda da satışın kolaylaşmasına yardımcı olacak şartların oluşmasını sağlamaktir.

- Amaç, değer yaratma yolu ile müşteri memnuniyetini ve müşteri sadakatini sağlamaktır.

Turizm pazarlaması ise, Dünya Turizm Örgütü (WTO) tarafından; “Turizm işletmesinin maksimum kazanç hedefine uygun olarak, turistik ürünle ilgili seçim yapma sürecinde ihtiyaç duyulan kararlarm alınmasına yönelik yönetim felsefesidir" şeklinde tanımlanmaktadır. Tanımlara göre turizm pazarlamasında temel amaç karlılığ artırmaktır (Coltman, 1989). Turizm pazarlamasında ürün kavramı, ürünün satışına değil, görevi misafir memnuniyetini sağlamak olan müşteri odaklılığına dönüşmüştür. Bu nedenle, pazarlamada misafirlerle iyi ilişki kurmak, onların ihtiyaçlarını belirlemek ve ihtiyaçlarını karşılayacak mal ve hizmetleri sunmak gerekir. Dolayısıyla bugünkü pazar, ürün veya hizmetler için doğru müşteri bulmak değil, müşteri için doğru ürün ve hizmetleri sunmakla ilgilidir (Prasanna, 2013, s.15). Bu noktada turizm pazarlaması, bu amaçlar doğrultusunda hareket etmeyi öngören bir yönetim unsuru olarak karşımıza çıkmaktadır. Dolayısıyla turizm pazarlaması bir yönetim olgusu içerinde barındırılır. Turizm pazarlama yönetiminin yapacağı görevler arasında pazara ve tüketiciye yönelik araştırmalar yapmak, talep tahminlerinde bulunmak, pazarın arzu edeceği çekici ürünler konusunda seçimler yapmak yer almaktadır. Sonuç olarak turizm pazarlamasının görevlerinden biri turizm pazarlaması bağlamında yer alan tüketiciler, (turistler) üzerine araştırmalar ve incelemeler yapmak, diğeri ise elde edilen beklentiler doğrultusunda pazarın talep etme olasıllğı yüksek ürünleri veya pazarlama bileşenlerini oluşturmaktır denilebilir (Altunışık, 2009, s.8-47).

\section{Turizm İşletmelerinde Pazarlama Karması}

Kotler, (2003, s.16) pazarlama karmasını "modern pazarlama teorisinin gereksinimlerinden birisi olduğunu" belirtmektedir. Kotler (2003) pazarlama karmasını "işletmelerin hedef pazarlarındaki satışların belli seviyede tutmak için kullandıkları pazarlama değişkenlerinin karması" şeklinde tanımlamaktadır. Pazarla- 
ma karması, misafir istek ve ihtiyaçlarının karşılanması amacı ile yapılan tüm pazarlama faaliyetlerinin bileşkesidir. Pazarlama karması konusu ile ilgili verilecek kararlar, misafir tatmini, otel işletmelerinin karlı bir biçimde işlevselliği ve turizm işletmelerinin varlıklarını devam ettirebilmeleri açısından önemlidir. Misafir istek ve ihtiyaçlarının karşılanması ve misafir memnuniyeti oluşturulmasında, doğru pazarlama karması unsurlarına karar verilmesi hayati derece önemlidir. Pazarlama karmasıyla ilgili kararlar otel işletmelerinin başarısının temel unsurudur (Çakıcı, Atay ve Harman, 2008, s.69-87). Pazarlama yönetiminde iki ana görev bulunmaktadır. Bunlardan birincisi, uygun bir pazar seçmek, ikincisi ise seçilen pazar veya pazarlara uygun pazarlama karması oluşturmaktır. Pazarlama karması, yönetim açısından yönetimin almak zorunda olduğu karar alanlarını gösterir. Pazarlama karması, kavram olarak ilk kez Borden (1964) tarafından kullanılmış ve Borden (1964) pazarlama karmasının, yöneticilerin, etkin pazarlama stratejileri meydana getirebilme sürecinde, etkili olduğunu vurgulamıştir.

1960'lı yıllardan günümüze kadar her süreçte pazarlama karması unsurlarında bazı değişiklikler olmuş ve pazarlama karması elamanlarının sayısıyla ilgili farklı çalışmalar yapılmıştır. McCarthy (1960) literatürde pazarlamada 4P olarak bilinen kavramı (ürün, fiyat, dağıtım, tutundurma) geliştirmiştir (Ünalan, 2017, s.106). Geleneksel olarak üzerinde fikir birliği bulunan pazarlama karması unsurları 4 tane olup; mamul (ürün), fiyat, tutundurma ve dağıtım ile ilgili kararlar şeklinde tanımlanmaktadır. Bu kararlar genel olarak aşağıdaki şekildedir; (Blythe ve Jim aktaran Taşoğlu, 2009, s.30-31, Rızaoğlu, 2004, s. 171-292, Mucuk, 2004, s.123-283, Kozak, 2014, s.125-240)

Ürün: Ürün, müşterilerin ihtiyaçlarına cevap verebilecek değişim veya tüketim için pazara sunulan her şeydir. Misafirlerin isteklerine uygun olmalıdır. Turizmde ürün genellikle soyut özellik gösterir. Müşterilerin tatil seyahatleri boyunca yararlandıkları ve satın aldıkları mal ve hizmetlerin oluşturduğu deneyimlerin toplamıdır. Ürün hizmetin üretilmesi ve sunulmasindan oluşmaktadır.

Fiyat: Ürünün bedeli ya da temsil ettiği değeridir. Fiyat hem mal sahibi, hem de alıcı için bir mal veya hizmetin değerini temsil eder Tüketicilerin ürünleri kullanma veya satın alma yoluyla elde ettikleri değerlerin toplamıdır. Fiyat, müşteriler açısından belli ürün ya da hizmetlerin elde edilmesine 
karar verilmesi aşamasında önemli bir etkendir. Hizmetlerde fiyatlandırma, ürünlerde olduğundan daha zordur. Misafirlerin ödedikleri paraya karşılık elde ettikleri kalite algıları konusunda sorunlar yaşanabilir. Bu durum ürünün somut özelliği ile ilişkilendirilebilir.

Dağıtım: Doğru" ürünü hedef pazara ulaştırmakla ilgili tüm kararları içerir. Genel olarak dağıım kanalı mal ve hizmetlerin pazarlanmasını sağlayan işletme içindeki bazı bölümler ile işletmenin dışında bulunan pazarlama kurumlarıdır. Hizmetlerin, dokunulmazlık, ayrılmaz, bozulabilirlik ve etkileşim gibi özelliklerin ürünlerinden farklı olduğunu düşünmektedir. Dolayısıyla, ürün pazarlamasında kullanılabilen geleneksel dağıtım kanalları, hizmet pazarlamasında kullanılamaz. Hizmetler satıştan ayrılamaz; üretim ve tüketim eş zamanlıdır, ürünler aynı zamanda oluşturulmalı ve satılmalıdır. Ayrıca ürün, hedef müşterilerin kolayca satın alabilecekleri yerlerde bulunabilmelidir. Otel işletmelerinde dağıtım kanalları ters işler, ürünler müşteriye gitmez, müşteriler hizmetin üretildiği yere gelirler.

Tutundurma: Tüketicileri ürünler hakkında bilgilendirmek ve bu ürünleri satın almaya teşvik etmek için atılan adımlara "tutundurma" denir. Ürünlerin hedef pazarda kabul görebilmesi için müşterilerin ikna edilmesine yönelik yapılan iletişim etkinlikleridir. Reklam, satış tutundurma, kişisel satış, halkla ilişkiler ve diğer iletişim araçlarıdır. Hizmet sektöründe, hizmetin özelliklerinden dolayı kişisel satışta insan unsurunun önemi son derece artmıştır.

Hizmet endüstrilerinin gelişmesiyle hizmet pazarlaması ağırlık kazanmıştır. Bu durumun sonucu klasik dörtlü pazarlama bileşenleri asıl kabul edilmekte birlikte yardımcı unsurların eklenmesi gerektiği düşünülmektedir. 4P’nin yeterli olmadığını düşünen Booms ve Bitner (1981, s. 47-51) ek olarak; insanlar, süreç ve fiziksel kanıtlar olmak üzere üç bileşen daha eklemişlerdir (Ünalan, 2017, s.103-107, Constantinides, 2006, s.407-438). Bu durum sonucu oluşan $7 \mathrm{P}$, turizm sektöründe turizm pazarlama karması unsurları olarak kullanılmaya başlamıştır. İnsan, fiziksel kanıt ve süreç olmak üzere üç bileşen şu şekilde açıklanmaktadır: ( Sarker, Aimin ve Begum, 2012, s.273-274, Shostack, 1977, s.73-80, Mohammed ve Pervaiz, 1995, s. 415)

İnsan: İnsan, hizmet sunumunda yer alan ve alıcının algılarını etkileyen tüm insan oyuncuları olarak tanımlanır; Kısaca firmanın müşterileri, personelleri ve hizmet ortamındaki diğer müşteriler. Otel işletmeleri hizmet 
odaklıdır. Hizmeti sunanda alanda insandır. Üretim ve tüketimin eşzamanlı olması nedeniyle otel personeli ürün kalitesinin müşteri algılamalarını etkilemekte önemli bir role sahiptir. Personel ürünün bir parçasıdır ve bu nedenle ürün kalitesi servis sağlayıcının kalitesinden ayrılamaz Bu nedenle, çalışanların kalitesine özel bir önem vermek ve performansların izlemek önemlidir. Bu, hizmetlerde özellikle önemlidir; çünkü çalışanların değişken performansları, değişken verimliliğe neden olabilmektedir.

Katılımclar, hizmeti satın alan müşteriyi ve hizmet ortamındaki diğer müşterileri de içerir. Örneğin, bulunulan ortamdaki insanların sayısı ve davranışları kısmen de olsa ortamdaki memnuniyete etki edecektir. Hizmet sunumunda rol alan ve müş̧terilerin algılarını etkileyen tüm insanlar ile müşterilerle doğrudan iletişimde bulunan çalışanlar, diğer çalışanlar, müşteriler, hizmet ve sunum aşamasında o mekânda bulunan diğer müşteriler insan unsurunu oluşturmaktadır.

Fiziksel kanitlar: Fiziksel kanıtlar, hizmetin verildiği ortamı ve performansı kolaylaştıran somut malları ifade eder. Hizmeti temsil eden bütün maddi faktörleri içerir. Müşteriler sağlanan hizmetin kalitesini değerlendirmek için somut unsurlardan faydalanır. Bu nedenle, fiziksel kanıtlar son derece önemlidir. Fiziksel kanıtlar yöneticilerin işletmelerini göstermek için kullandıkları bir araçtır Dolayısıyla, hizmeti somut hale getirme ihtiyacı oldukça büyüktür. Otel işletmelerinde, fiziksel çevre ürünün kendisinin bir parçasıdır ve dekor, mobilyalar, kullanılan malzemelerin kalitesi, manzara, bahçe düzenlemesi vb. somut unsurlar müşterilerin bekleyecekleri hizmet kalitelerinin değerlendirilmesinde bir iletişim unsuru olarak etkili olmaktadir

Süreç: Hizmetin edinildiği işlemlerin akış faaliyetlerine süreç adı verilir. Hizmetlerin müşteriye ulaşmasını sağlayan prosedür ve faaliyetlerin akışına süreç denir. Hizmet sunumunun ilk etkinliğinden son etkinliğine kadar geçen süre veya katılımclların hizmet sunumunu gerçekleştirmek için takip etmesi gereken adımların sayısı şeklinde tanımlanabilir. Turizm sektöründe müşteriler süreç aşamasında yer alırlar.

Yukarda belirtildiği üzere turizm pazarlaması kapsamında 4P yerine 7P yaklaşımının daha uygun olacağı ifade edilmiştir. Ancak literatürde bazı araştırmacıların 4P veya 7P türü yaklaşımların pazarlamayı işletme perspektifinden bakışı yansıttığı ve dolayısıyla da tüketicilerin isteklerini ve beklentilerini değerlendirmede yetersiz kaldığını iddia ederek tüketici odak- 
lı pazarlama karmasının geliştirilmesinin gerekli olduğunu ifade etmektedirler.

1960'lı yılların başlarında tanımlanmış olan ve pazarlamada 4P olarak adlandırılan elemanlar, genel olarak pazarlama çerçevesini oluşturmaktadır. Yıllardır kullanılan ve pazarlamada 4P olarak bilinen ürün ve hizmet, fiyat, dağıtım ve tutundurma faaliyetleri aslında, pazarlamanın olmazsa olmazidır. Ancak günümüzün küresel rekabet ortamı azalan karlılıklar gibi önemli sorunların baskısı altında olan iş dünyasında klasik 4P ile bu baskının üstesinden gelebilmek mümkün değildir. Bu nedenden dolayı C'lere ihtiyaç duyulmaktadır. İşte 4C diye adlandırılan diğer faktörler, klasik 4P'nin karlılık hedefine ulaşmasına yardımcı olan unsurlar olarak karşımıza çıkmaktadır. Lauterbor (1990a) dört ürün odaklı "P”'nin, tüketici odaklı bir versiyonu olan " $4 C$ " sınıflandırmasını önermiştir. " $4 C$ " ile oluşan yeni bakış açısı ile misafirler odak noktası durumuna gelmiştir. Otel işletmesini "otel hizmeti" olarak pazarlamak zordur. Otelin hizmeti, çalışanları, havuzu, kafeteryaları, denizi, temizliği, plajı gibi bir veya birkaç özelliği otel işletmesinin “ $\mathrm{C}^{\prime \prime}$ 'lerini ifade eder. Otel işletmesine müşteri çekebilmenin günümüz iş dünyasındaki en önemli aktörleri " $\mathrm{C}$ "'lerdir. Bu nedenle " $4 \mathrm{P}$ " ve " $4 \mathrm{C}$ " bir arada, işletme adına hedef pazara, birlikte uygun kombine edilerek servis edilebilmektedir. Bu nedenle işin özüne odaklanmak yerine sadece $\mathrm{P}^{\prime}$ lerin sayısı üzerinden değerlendirme yapılmamalıdır. C'ler değerlendirilmezse ürün/hizmet hedef pazarın zihninde konumlandırılamaz. Otelin mimari yapısı, havalandırma, yemekleri misafirlerin kabul edeceği ve memnun kalacağı tarzda olabilir. Ancak hizmette, müşteri ilişkileri adına olumsuzluklar veya yetersizlikler varsa somut unsurlarm olumlu olmasl, misafirin memnuniyetine yeterli gelmemektedir. Son olarak, Moharana (Moharana'dan aktaran Halaj ve Brodrechtova, 2015) müşterinin bakış açısından 7P'nin, tüketici odaklı bir versiyonu olan 7 C sınıflandırmasını önermiştir (Halaj ve Brodrechtova, 2015, Lauterborn, 1990, Bilge, 2015, s.156-159).

1980'li yllardan sonra hizmet pazarlamasındaki farklılıklar önem kazanmış, bu durum turizm sektörüne de yansımış, turistik hizmet ve ürün oluşturan otel işletmeleri de pazarlama açısından farklı stratejiler geliştirmeye başlamışlardır. Otel işletmelerinde hizmet pazarlaması unsurları tüketici odaklı pazarlama karma elemanlarını ön plana çıkartmakta ve günümüz modern pazarlama yaklaşımında, otel işletmelerinde, hizmetin sunulduğu her aşamada aynı anda üretici ve tüketici konumunda olan insan faktörü 
önem kazanmaktadır. Bu kapsamda öne sürülen yaklaşımda, tüketici bakış açısını da yansıtması açısından "7P" yaklaşımı, "7C yaklaşımı olarak değiştirilmiştir. İki farklı yaklaşım aşağıda farklı açıdan ele alınmıştır. Şeklin sol tarafında işletme bakış açısından turizm pazarlama karması, sağ tarafında ise tüketici bakış açısından turizm pazarlama karması yer almaktadır (Güler, 2009, s.23-61),

Tablo 1. $7 P^{\prime}$ den $7 C^{\prime}$ ye geçiş

\begin{tabular}{lll}
\hline Firma penceresinden - 7P & & Tüketici penceresinden - 7C \\
\hline Product (ürün) & $>$ & Customer Value (müşteri değeri) \\
\hline Price (fiyat) & $>$ & Cost to Customar ( müşteriye maliyet) \\
\hline Promotion (dağıtım) & $>$ & Convenience (kolaylik,erişilebilirlik \\
\hline Place (tutundurma) & $>$ & Communication (iletişim) \\
\hline People (insan) & $>$ & Consideration (önemseme) \\
\hline Proceses (süreç) & $>$ & Coordination (koordinason) \\
\hline Physical Evidence (fiziksel kanıtlar) & $>$ & Confirmation (onylama) \\
\hline
\end{tabular}

Altunışık (2009, s.47)

Tablo 1. Incelendiğinde şu sonuçlara varmak mümkündür (Halaj ve Brodrechtova, 2015, Bulut, 2012, s.11-13):

- Ürün'ün yerine "müşteri değer"i geçmiştir. Bu anlayışa göre, ürünün özellikleri kadar tüketicilere kattığı değer önemlidir. Kısaca ürünlerin misafir ihtiyaçlarını karşılama gücü ile onlara sağladığı değerlerdir

- Fiyat'ın, yerine "maliyet" geçmiştir. Misafirler kısıtlı kaynaklarla ihtiyaçlarını karşılamak isterken, işletmeler, maliyetlerini artırmadan müşteri değerini artırma yollarına yoğunlaşmalıdır. Birisinin yalnızca satın almak istediği şeyleri satabilirsiniz. " Maliyet " aracı, müşterilerin istek ve ihtiyaçlarını karşılamak için yapılan tüm maliyet anlamına gelir. Maliyet sadece, ürünün veya hizmetin fiyatını değil, aynı zamanda doğru ürünün bulunması için gereken zaman, satın alınacak sürücünün maliyeti, enerji maliyeti vb. unsurları da kapsar.

- Dağıtım'ın yerine "erişilebilirlik" geçmiştir. İşletmeler, ürünlerini istenilen yerde, istenilen zamanda ulaşılabilir kılmalıdır

- Tutundurma'nın yerine "iletişim" geçmiştir. Günümüzde tüketiciler, baskıcı ve yoğun bir şekilde gerçekleştirilen tutundurma çabalarının yerine, ürünün sağlayacağı faydanın kendilerine çift yönlü iletişim ile iletilmesini beklemektedirler. Özellikle internet teknolojileri ile sosyal medya bu iletişim için önemli faydalar sağlamaktadır. Tutundurma şir- 
ketlerin insanları satın almaya ikna etme yollarını önerirken "iletişim", müşterilerin tedarikçilerine geri bildirimleri de içeren iki yönlü bir süreçtir

- İnsan unsurunun yerine "önemseme" geçmiştir. Bu duruma göre, misafirler ürün tercih etmekle işletmeden ilgi ve itibar beklemektedir. Bu durum ise pazarlama faaliyetlerinin zamanla kişiselleşmeye doğru yol almasiyla ilgilidir.

- Fiziksel belirti yerine "onaylama" geçmiştir. Hizmetin üretildiği ortam, üretimin yapıldığı yerin şekli, renkler, araçlar, personel kıyafetleri, mobilyalar, logo gibi unsurlardan oluşan memnuniyet, tüketicilerin hizmeti onaylanması demektir.

- Süreç yerine "eş güdüm" geçmiştir. Hizmetlerin tüketicilere ulaşmasıyla ilgili tüm faaliyetler, misafir eş güdümü doğrultusunda yapılmalıdır. "Eş güdüm yaklaşımı", tüketicilerin sürecin içinde yer alması demektir.

\section{Yöntem}

\section{Çalışmanın amacı, önemi ve yöntemi}

Küçük otellerin evrensel olarak kabul görmüş kesin bir tanımı (Morrison ve Thomas, 1999, s. 148) ve kriterleri konusunda kesin bir fikir birliği bulunmamasına ( Quah ve Chan, 2008) rağmen, Batman (2004, 31-33) ölçekleri bakımından, 25 veya daha az odaya sahip otelleri "çok küçük oteller", 25 ile 99 oda arasında odaya sahip otelleri "küçük oteller" olarak sınıflandırmaktadır, Buhalis ve Main, $(1998,198) 50$ odanın altında odaya sahip olan otelleri küçük ve orta büyüklükteki oteller, Ingram vd., (2000, s. 212) ise 50 odanın altındaki odaya sahip otelleri küçük oteller olarak sınıflandırmaktadır. Çalışmada bölgede bulunan elli oda'nın altında odaya sahip oteller küçük oteller olarak değerlendirilmektedir.

Bu çalışmada, küçük otel işletmelerinde yöneticilerin pazarlama karması bileşenleri önem algılarının (7p ve 7c açısından) tespit edilmesi amaçlanmıştır. Çalışmada Mersin İline bağlı, turizmin gelişmekte olduğu Silifke ilçesinde bulunan küçük sayfiye otel işletmeleri yöneticilerinin algıları hem üretici (7p), hem de tüketici (7c) odaklı olarak tespit edilmeye çalışılmıştır. Otel işletmelerine yönelik 7p ve 7c odaklı çok fazla çalışma yapılmadığı için çalışma, otel yöneticileri ile daha sonra yapılacak olan çalışmalara yol göstermesi açısından önem arz etmektedir. 
Çalışmada veriler anket yöntemi ile toplanmıştır. Öncelikli olarak ilgili literatür incelenmiş, konuyla ilgili Altunışık (2009)'ın çalışmalarından faydalanılarak bir anket formu hazırlanmıştır. Birinci bölümde demografik bilgilerle ilgili sorular sorulmuştur. Ardından küçük otel işletmelerinde yöneticilerin pazarlama karması bileşenlerinin önem algıları ile ilgili çoktan seçmeli sorular (1-çok önemliden, 5-çok önemsize doğru) sorulmuştur. Silifke Turizm Ofisinden, Silifke'de faal durumda 61 küçük sayfiye oteli olduğu bilgisi alınmıştır. Bazı yöneticilere ulaşılamaması ve bazı yöneticilerin de farklı nedenlerle anket yapmak istememeleri sonucu 46 otel yöneticisine anket yaptırılabilmiştir.. Yüz yüze görüşmelerle otellerde bulunan yöneticilerden sorulara cevap vermeleri istenmiş ve yöneticilerin cevapları işaretlenmiştir. Elde edilen veriler, istatistiksel SPSS paket programı ile değerlendirilmiş, mevcut bulgular, yüzde-frekans veri tablolarına dönüştürülmüştür.

Tablo 2. Katılımcılarnn demografik özelliklerine ait bulgular.

\begin{tabular}{|c|c|c|}
\hline Yaş & $\mathbf{N}$ & $\%$ \\
\hline $20-29$ & 10 & 21,7 \\
\hline $30-39$ & 10 & 21,7 \\
\hline $40-49$ & 16 & 34,8 \\
\hline 50 yaş ve üstü & 10 & 21,7 \\
\hline Toplam & 46 & 100 \\
\hline Cinsiyet & $\mathbf{N}$ & $\%$ \\
\hline Erkek & 40 & 87,0 \\
\hline Bayan & 6 & 13,0 \\
\hline Toplam & 46 & 100 \\
\hline Eğitim durumu & $\mathbf{N}$ & $\%$ \\
\hline İlköğretim & 6 & 13,0 \\
\hline Lise & 21 & 45,7 \\
\hline Üniversite & 19 & 41,3 \\
\hline Toplam & 46 & 100 \\
\hline Mesleği & $\mathbf{N}$ & $\%$ \\
\hline Sahibi & 24 & 52,2 \\
\hline Müdür & 11 & 23,9 \\
\hline Departman amiri & 7 & 15,2 \\
\hline Diğer & 4 & 8,7 \\
\hline Toplam & 46 & 100 \\
\hline Sektör tecrübesi & $\mathbf{N}$ & $\%$ \\
\hline $1-5$ yıl arası & 14 & 30,4 \\
\hline $6-10$ yıl arası & 7 & 15,2 \\
\hline $11-15$ yıl arası & 13 & 28,3 \\
\hline 16 yll ve üzeri & 12 & 26,1 \\
\hline Toplam & 46 & 100 \\
\hline Turizm eğitimi alma durumu & $\mathbf{N}$ & $\%$ \\
\hline
\end{tabular}




\begin{tabular}{lll}
\hline Aldım & 11 & 24 \\
\hline Almadım & 35 & 76 \\
\hline Toplam & $\mathbf{4 5}$ & $\mathbf{1 0 0}$ \\
\hline
\end{tabular}

Tablo 2'ye göre; Katılımcıların \% 21,7'si 20-29 yaş arasında,\% 21,7'si 30-39 yaş aralığında, \% 34,8'i 40-49 yaş aralığında, \% 21,7'si ise 50 yaş ve üzerindedir. Katılımcıların \% 13'ü kadın, \% 87'si ise erkektir. Ayrıca, katılımcıların çoğunluğu (\% 45,7'si ) lise ve üniversite (\% 41,3'ü ) mezunu ve \% 76,1'i işletme sahibi veya yöneticisidir. Katılımcıların büyük çoğunluğu 1-5 yıllık (\% 30,4'ü) tecrübeye sahiptir. Katılımcılardan sadece 11 kişi (\% 24) turizm eğitimi almış, diğerleri turizmle ilgili her hangi bir eğitim almamıştır (diğerleri mühendislik, su ürünleri gibi bölümlerden mezundur).

Tablo 3. İşletme özellikleri ile ilgili bulgular

\begin{tabular}{lll}
\hline Oda Sayısı & $\mathbf{N}$ & $\mathbf{\%}$ \\
\hline 20 den az & 18 & 39,1 \\
\hline $20-39$ arası & 24 & 52,2 \\
\hline $40-49$ arası & 4 & 8,7 \\
\hline Toplam & $\mathbf{4 6}$ & $\mathbf{1 0 0}$ \\
\hline Yatak Sayısı & $\mathbf{N}$ & $\mathbf{\%}$ \\
\hline 40 yataktan az & 12 & 26,1 \\
\hline $40-79$ yatak arası & 18 & 39,1 \\
\hline $80-119$ yatak arası & 14 & 30,4 \\
\hline 120 yatak ve üzeri & 2 & 4,3 \\
\hline Toplam & $\mathbf{4 6}$ & $\mathbf{1 0 0}$ \\
\hline Personel Sayısı & $\mathbf{N}$ & $\mathbf{\%}$ \\
\hline $1-5$ & 24 & 52,2 \\
\hline $6-10$ & 16 & 34,8 \\
\hline $11-15$ & 5 & 10,9 \\
\hline 15 ve üzeri & 1 & 2,1 \\
\hline Toplam & $\mathbf{4 6}$ & $\mathbf{1 0 0}$ \\
\hline
\end{tabular}

Tablo 3'e göre otel işletmelerin büyük çoğunluğu 39 oda'dan az (\% 91,3) oda ve 40 yataktan fazla yatağa sahiptir. 16 oda (\% 34,7) 80 ve üzeri yatağa sahipken 2 oda $(\% 4,3) 120$ ve üzeri yatağa sahiptir. Ayrıca işletmelerin büyük çoğunluğu (\% 87) 10 personelden az personele sahiptir. 
Tablo 4. Pazarlama karması önem algılar ile ilgili bulgular (1-çok önemliden, 5-çok önemsize doğru)

\begin{tabular}{|c|c|c|c|c|c|c|c|c|c|c|}
\hline $7 \mathrm{P}$-yönetici olarak & 1 & & 2 & & 3 & & 4 & & 5 & \\
\hline & $\mathbf{N}$ & $\%$ & $\mathbf{N}$ & $\%$ & $\mathbf{N}$ & $\%$ & $\mathbf{N}$ & $\%$ & $\mathbf{N}$ & $\%$ \\
\hline Ürün & 25 & 54,3 & 7 & 15,2 & 6 & 13,0 & 3 & 6,5 & 5 & 10,9 \\
\hline Fiyat & 21 & 45,7 & 8 & 17,4 & 4 & 8,7 & 4 & 8,7 & 9 & 19,6 \\
\hline Yer (Dağıtım) & 9 & 19,6 & 15 & 32,6 & 11 & 23,9 & 4 & 8,7 & 7 & 15,2 \\
\hline Tutundurma & 15 & 32,6 & 10 & 21,7 & 7 & 15,2 & 7 & 15,2 & 7 & 15,2 \\
\hline Hedef Kitle (Müşteri) & 22 & 47,8 & 5 & 10,9 & 4 & 8,7 & 3 & 6,5 & 12 & 26,1 \\
\hline Süreç & 9 & 19,6 & 9 & 19,6 & 9 & 19,6 & 7 & 15,2 & 12 & 26,1 \\
\hline $\begin{array}{l}\text { Fiziksel } \\
\text { Olanaklar(Kanitlar) }\end{array}$ & 11 & 23,9 & 6 & 13,0 & 9 & 19,6 & 4 & 8,7 & 16 & 34,8 \\
\hline 7C- müşteri olarak & 1 & & 2 & & 3 & & 4 & & 5 & \\
\hline & $\mathbf{N}$ & $\%$ & $\mathbf{N}$ & $\%$ & $\mathbf{N}$ & $\%$ & $\mathbf{N}$ & $\%$ & $\mathbf{N}$ & $\%$ \\
\hline Tüketici Değeri & 17 & 37,0 & 15 & 32,6 & 3 & 6,5 & 1 & 2,2 & 10 & 21,7 \\
\hline Maliyet & 26 & 56,5 & 8 & 17,4 & 5 & 10,9 & & & 7 & 15,2 \\
\hline $\begin{array}{l}\text { Kolaylık } \\
\text { (Erişilebilirlik) }\end{array}$ & 19 & 41,3 & 9 & 19,6 & 6 & 13,0 & 4 & 8,7 & 8 & 17,4 \\
\hline İletişim (Tüketiciyle) & 14 & 30,4 & 7 & 15,2 & 10 & 21,7 & 7 & 15,2 & 8 & 17,4 \\
\hline $\begin{array}{l}\text { Değer Verilme } \\
\text { (önemseme) }\end{array}$ & 19 & 41,3 & 5 & 10,9 & 8 & 17,4 & 6 & 13,0 & 8 & 17,4 \\
\hline $\begin{array}{l}\text { Koordinasyon } \\
\text { (Süreç) }\end{array}$ & 8 & 17,4 & 9 & 19,6 & 14 & 30,4 & 5 & 10,9 & 10 & 21,7 \\
\hline Onaylama(Teyit) & 13 & 28,3 & 9 & 19,6 & 8 & 17,4 & 3 & 6,5 & 13 & 28,3 \\
\hline
\end{tabular}

Tablo 4'e gore 7P pazarlama karmasına yöneticilerin verdikleri cevaplara bakıldığı zaman ulaşılan sonuçlar şunlardır; Yöneticilerin büyük çoğunluğu ürün $(69,5)$, fiyat $(63,1)$, hedef kitle $(58,7)$, tutundurma $(54,3)$, yer $(52,2)$ pazarlama karması elemanlarını 1 ve 2 olarak işaretlemişlerdir. Süreç ve fiziksel kanıtlar 1 ve 2 şıklarının en az işaretlendiği şıklardır. Ayrıca bu iki seçenek 4 ve 5 şıklarında en fazla işaretlenen şıklardır. Süreç ve fiziksel kanıtlar diğer şıklara göre öneminin yeterince algılanmadığı düşünülmektedir. En önemli iki unsurun ürün ve fiyat olarak algılandığı görülmektedir.

Tablo 4'e gore 7C pazarlama karmasına yöneticilerin verdikleri cevaplara bakıldığı zaman ulaşılan sonuçlar şunlardır; Yöneticilerin büyük çoğunluğu tüketici değeri $(69,6)$, maliyet $(63,9)$, kolaylık $(60,9)$, değer verme $(52,2)$, iletişim $(45,6)$, pazarlama karması elemanlarını 1 ve 2 olarak işaretlemişlerdir. Onaylama $(34,8)$, iletişim $(32,6)$, koordinasyon $(32,6)$, 4 ve 5 şıklarının en çok işaretlendiği şıklardır. Koordinasyon en çok 3 olarak işaretlenmiştir. Sonuç olarak maliyet, tüketici değeri ve erişilebilirliğin çok önemli olduğu, koordinasyon, onaylama ve iletişime yeterli önemin verilmediği görülmektedir. 


\section{Sonuç}

Sonuç olarak demografik bilgilere göre katılımcıların çoğunluğu erkek, 40 yaşın üstünde, eğitimli ve işletmenin sahibi veya yöneticisi (76,1 \%)olduğu görülmektedir. Ayrıca 11 kişi (24\%) turizm bölümü mezunudur. Diğerleri mühendislik, su ürünleri gibi farklı bölümlerden mezundur. İşletmelerin çoğunluğu ( \%87) 10 personelden az personel çalıştıran küçük otel işletmelerinden oluşmakta ve bu işletmelerin 40 odadan az oda ve 40 yataktan fazla yatağa sahip oldukları 2 otel'in (4,3\%) 120'den fazla yatağa sahip olduğu görülmektedir. Bulgulara istinaden işletmelerin yatak kapasitelerinin yüksek, çalışan sayılarının düşük olduğu sonucuna ulaşılmıştır.

Çalışmada yöneticiler tarafından ürün bağlamında (7P) en önemli pazarlama karması unsuru olarak "ürün" ve "fiyat" seçeneklerinin algılandığı. "süreç" ve "fiziksel kanıtlar" unsurlarının öneminin yeterince algılanmadığı sonucuna ulaşılmıştır. 7C kapsamında ise "maliyet", "tüketici değeri" ve "erişilebilirlik" unsurlarının çok önemli unsurlar olarak algılandığı, "koordinasyon", "onaylama" ve " iletişim" unsurlarının öneminin yeterince alg1lanmadığı sonucuna ulaşılmıştır. Bu durumun sebebinin yöneticilerin eğitimli olmalarına rağmen turizm eğitimi almamalarından kaynaklandığ1 düşünülmektedir. Ayrıca yöneticilerin, "süreç", "fiziksel kanıtlar", "koordinasyon" ve "iletişim" gibi unsurlara olan önem algılarının düşük olması, hizmeti ürün olarak önemsemedikleri, ürünler ve fiyatın onlar için önemli algılandığı için az sayıda personel ile çalıştıkları da düşünülmektedir.

Kısaca, küçük otel yöneticilerinin klasik pazarlama karması elemanlarının (4P ve 4C) önem algılarının yüksek olduğu, hizmet sektörü pazarlama karması unsurlarının (7P ve 7C) önem algılarının daha düşük olduğu sonucuna ulaşılmıştır. Konuyla ilgili Al-Debi ve Mustafa (2014, s.47), Sanıb vd. (2013, s.310), büyük otellerde yapmış oldukları çalışmalarda misafirlerin otel tercihinde fiyatın çok etkili olmadığı, Prapannetivuth (2015), Thvala ve Slabbert (2018) ve Buddhichiwin (2015) ise küçük otellere yönelik yapmış oldukları çalışmalarında pazarlama karma unsuru olarak (7P) fiziksel kanıtların da önemli olduğunu belirtmişlerdir. Çalışmada, fiziksel kanıtlara verilen önemin az olduğu, maliyet, fiyat ve tüketiciye değerin daha önemli alg1landığı yani, maddi unsurlara daha çok önem verildiği sonucuna da ulaşılmaktadır. Hizmet sektöründe yöneticilerden değer yaratan hizmet ve ürünlere öncelik vermeleri beklenmektedir. Daha çok fiyat değil, fiyatla birlikte 
değer yaratan çalısmalara önem verilmesi gerektiği, bu sürecin önemli bir çıktısı olarak kabul edilmektedir.

Günümüzde iletişim araçlarının etkinliğinin hızla artması tüm işletmeleri olduğu gibi küçük işletmeleri de etkilemiştir. Küçük otel işletmeleri de bu süreçte pazarlama yönetim sistemi konusunda yeni arayışlara yönelmişlerdir. Bu işletmeler, pazarlama karması faaliyetlerinin etkin bir şekilde yönetilmesi gerektiği, pazarlamanın insan ihtiyaçlarına yönelik çok sayıda eylemler bütününden oluştuğu, bir hedefe yönelik olması gerektiği, satışı destekleyici ve misafirler için değer yaratan unsurlar barındırması gerektiği gibi temel bileşenlerden oluştuğu gerçeği ile karşılaşmışlardır.

\section{Öneriler}

Yöneticilerin eğitim düzeyi yüksek olmasına rağmen, turizm eğitimi alan yöneticilerin sayısının çok az olduğu ve hizmet pazarlaması unsurlarının (7P) önem derecesini yeterince algılamadıkları düşünülmekte ve yöneticilere üniversiteler ve çeşitli kurumlardan konuyla ilgili danışmanlık hizmeti veya eğitimler almaları tavsiye edilmektedir. Ayrıca küçük otellerde az personel çalışmakta, personel sayısının artırılarak hizmet kalitesinin yükseltilmesi için yakın çevrede bulunan turizm liseleri ve üniversitelerden stajyer öğrenci temin etmeleri de tavsiye edilmektedir.

Daha önce dünyanın farklı yerlerinde yapılan çalışmalarda pazarlama karması unsurları içerisinde fiziksel kanıtlar önemli algılanırken yapılan çalışmada çok önemli algılanmamaktadır Küçük otel yöneticilerinin pazarlama karması önem algılarının nedenlerini de tespit etmeye yönelik yeni çalışmalar yapılabilir.

Çalışma sadece Mersin İline bağlı Silifke İlçesinde bulunan küçük sayfiye oteller üzerine yapılmıştır. Bu çalışma şehirlerde bulunan küçük otellerde, başka ülkelerde veya ülkenin farklı bölgelerinde bulunan küçük otellerde de yapılabilir. Ayrıca, çalışma sadece yöneticilerin 7P ve 7C önem algılarını tespit etmek amacıyla yapılmış olup ayn çalışma bölgedeki küçük otellere gelen tüketiciler üzerine de yapılabilir. 


\title{
EXTENDED ABSTRACT
}

\section{Attitudes of Managers Towards Marketing Mix In Small Size Hotel Businesses: An Application}

\author{
Kürşad Sayın - Abdullah Karaman \\ Selçuk University
}

Tourism sector is seen as a whole consisting of accommodation, transportation and dynamic marketing components. Therefore, marketing activities have importance in terms of hotel businesses. Increasing importance of small hotel businesses in the globalizing world depends on the administration of marketing mix properly.

Because touristic consumers' desires and expectations has changed, marketing mix has been prospered with new variables. Three new components have been added to product, price, location and promotion, which are the basic marketing components as the result of development in the service sector. These can be listed as human (providing service), physical elements, process (service process). Consumer-focused marketing mix (7c) has also been developed since this situation is insufficient to take account of consumer desires and expectations.

Because touristic consumers' desires and expectations has changed, marketing mix has been prospered with new variables the human factor is very important in hotel businesses. Because the service is in the production process both as a producer and as a consumer. For this reason, academic studies are evaluated together with the $7 \mathrm{p}$ approach as $7 \mathrm{c}$ in terms of reflecting the consumer's point of view.

In this study, the importance of marketing mix components of managers in small hotel enterprises is emphasized. The study was conducted in Silifke, a touristic region of Mersin province. A related questionnaire was prepared in the study after the related literature was reviewed. Questionnaires were filled in by interviewing face to face with the small hotel authorities in the region and the answers were evaluated and tabulated with the help of SPSS statistical package program. 
As a result, according to demographics, it is seen that the majority of respondents are male, over 40 years of age, educated, and the owner or manager of the enterprises $(76.1 \%)$. Also, 11 people $(24 \%)$ are graduates of the Department of Tourism. Others are graduates from different departments such as engineering, fisheries. The majority of enterprises (87\%) consisted of small hotel enterprises employing fewer than 10 staff, and these enterprises had fewer than 40 rooms and more than 40 beds, while 2 hotels (4.3\%) had more than 120 beds. Based on the findings, it was concluded that the bed capacity of the enterprises is high and the number of employees is low.

In the study, it was concluded that "product" and "price" options were perceived by managers as the most important marketing mix element in the product context (7P), while the importance of "process" and "physical evidence" elements was not adequately perceived. Under the context of 7C, it was concluded that the" cost"," consumer value "and" accessibility "elements were perceived as very important elements and that the" coordination"," approval " and" communication " elements were not adequately perceived. The reason for this situation is thought to be due to the managers being educated but not trained in tourism. It is also thought that managers have low perceptions of importance to elements such as "process", "physical evidence", "coordination" and "communication", that they do not care about service as a product, because products and price are perceived as important to them, and that they work with a small number of staff.

In short, it was concluded that the small hotel managers had higher importance perceptions of the classic marketing mix elements (4P and 4C) and lower importance perceptions of the service sector marketing mix elements (7P and 7C). About the subject, Al-Debi and Mustafa (2014, p.47), Sanib et al. (2013, p.310) have stated that price is not very effective in hotel preference of guests in their studies of large hotels while Prapannetivuth (2015), Thvala and Slabbert (2018) and Buddhichiwin (2015) have also stated that physical evidence (7P), as an element of marketing mix, is important in their study of small hotels. In the study, it is concluded that the importance given to physical evidence is less, that cost, price, and value to the consumer are perceived as more important, i.e., that material elements are given more importance. Managers in the service sector are expected to give priority to services and products that create value. It is considered as an important 
output of this process that the works that create value together with price, rather than price, should be given importance.

Today, the rapid increase in the effectiveness of communication tools has affected small enterprises as well as all enterprises. In this process, small hotel enterprises have also turned to new pursuits in the marketing management system. These enterprises confronted with the fact that marketing mix activities should be managed effectively, that marketing consists of a large number of actions aimed at human needs, that it should be targeted at a goal, that it should contain elements supporting sales and creating value for guests.

\section{Kaynakça / References}

Al-Debi, H. A., ve Mustafa, A. (2014). The impact of services marketing mix 7p's in competitive advantage to five stars hotel: Sase study Amman, Jordan. The Clute Institute International Academic Conference, Orlando, Florida, USA, 39-48.

Altunışı, R. (2009). Turizm işletmelerinde pazarlamanın temelleri ve iki farklı pencereden pazarlama yönetimi: üretici ve tüketici bakış açısı. C. Avcikurt, Ş. Demirkol, B. Zengin (Edit.), Turizm İşletmelerinin Pazarlamasında 7P ve 7C, İstanbul:Değişim Yayınları, ISBN: 978-605-4031-12-2.

Batman, O. (2004). Otel İşletmeleri. Ş. Demirkol ve B. Zengin (Edit), Turizm İsletmeleri içinde, (s.81-117). İstanbul: Değişim Yayınları,

Bilge, A. (2015). Otel işletmelerinde pazarlama. Abdullah Karaman (Edit), Otel İşletmeciliği içinde, s.156-159, Eğitim Yayınevi, Konya.

Blythe, J. (2001). Pazarlama İlkeleri. İstanbul: Bilim Teknik Yaynları.

Booms, B., H., Bitner, M., J. (1981). Marketing strategies and organization structures for service firms in Donnely, J.H., George, W.R. (Eds), Marketing of Services, Conference Proceedings: Amerikan Marketing Association, Chicage, IL, 47-51. http://drkellypage.com/uncategorized/marketings-evolution/ adresinden 30.04.2017 tarihinde erişilmiştir.

Borden, N., H. 1964. The Concept of the marketing mix. Journal Of Advertising Research, $4(2), \quad 2-7 . \quad \quad$ http://www.guillaumenicaise.com/wpcontent/uploads/2013/10/Borden-1984 The-concept-of-marketing-mix.pdf. adresinden 30.04.2017 tarihinde erişilmiştir. 
Buddhichiwin, P. (2015). The marketing mix in small Hotels: the case of Samui, Thailand. Available Online at http://ircconferences.com/ Book of Proceedings published by (c) International Organization for Research and Development - IORD, ISSN: 2410-5465 Book of Proceedings ISBN: 978-969-7544-00-4. https://docplayer.net/20990674-The-marketing-mix-in-small-hotels-the-case-ofsamui-thailand.html adresinden 01.05.2020 tarihinde erişilmiştir.

Buhalis, D., Main, H. (1998). Information technology in peripheral small and medium hospitality enterprises: strategic analysis and critical factors.Journal of Contemporary Hospitality Management, 10(5), 98 - 202. MCB University Press, ISSN 09596119 ,

Bulut, E. (2012). Pazarlama iletişiminde yeni yaklaşımlar kapsaminda sosyal medya uygulamalan ve etkili kampanya örnekleri. Yüksek Lisans Tezi, T.C. İstanbul Kültür Üniversitesi Sosyal Bilimler Enstitüsü, , Anabilim Dalı: İetişim Sanatları Programı: İletişim Sanatları, 11-13

Coltman, M., M. (1989). Tourism marketing. NY:Von Nostand Reinhold, s.10.

Constantinides, E. (2006). The marketing mix revisited: towards the 21st century marketing. Journal of Marketing Management, 22(3-4), 407-438. DOI: 10.1362/026725706776861190, ,

Coviello, N., Winklhofer, H., ve Hamilton, K. (2006). Marketing practices and performance of small service firms; an examination in the tourism accommodation sector. Journal of Service Research, Sage Publications, 9(1), 38. DOI: 10.1177/1094670506289533,

file:///C:/Users/k\%C3\%BCr\%C5\%9Fad/Downloads/CovielloetallSR2006\%20(1) .pdf. adresinden 30,04,2017 tarihinde erişilmiştir.

Çakıı, A. C., Atay,L. ve Harman,S. (2008). İstanbul'da faaliyet gösteren seyahat acentalarının pazarlama karması kararları üzerine bir araştırma. İstanbul Ticaret Üniversitesi Sosyal Bilimler Dergisi, 7(1), 69-87.

Dutsel, A., Y. (2015). Application of marketing mix strategies in hospitality business: a study of hotels in Abuja, FCT-Nigeria. Abuja Journal of Business and Management, 1(2), 31-43.

Erol, M. (2003). Turizm pazarlaması. ISBN: 975-8768-166, Bursa:Ekin Kitapevi. 43

Gundlach, G., T. ve Wilkie, W.,L. ( 2009). The American Marketing Association's new definition of marketing: perspective and commentary on the 2007 revision, Journal of Public Policy \& Marketing, 28(2), 259-264. https://www.unf.edu/ ggondlac/pdfs/pub 07.pdf adresinden 15.04.2020 tarihinde erişilmiştir. 
Güler, E., G.,(2009), Konaklama işletmelerinde tutundurma faaliyetleri ve Trakyadaki oteller üzerine bir araştırma, Marmara Üniversitesi IÏBF Dergisi 17(2), 23-261.

Halaj, D., Brodrechtova, Y. (2015). Marketıng decision-makıng of actors within the European forest biomass market, 23rd European Biomass Conference and Exhibition, 1-4 June 2015, Vienna, Austria.

Ingram, A., Jamieson, R., Lynch, P. ve Bent, R. (2000). Questioning the impact of the 'graduatization'of the managerial labour force upon the management of human resources in the Scottish hotel industry, Journal of Consumer Studies $\mathcal{E}$ Home Economics, 212-222. file:///C:/Users/k\%C3\%BCr\%C5\%9Fad/Downloads/Questioning the impact of the graduatiza\%20(1).pdf adresinden 30.04 .2020 tarihinde erişilmiştir.

Kotler, P., (2003). Marketing management: Analysis, planning, implementation and control. New Jersey: Prentice-Hall International Inc, Englewood

Çakıcı, A.,C., Atay,L., ve Harman,S. (2008), İstanbul'da faaliyet gösteren seyahat acentalarının pazarlama karması kararları üzerine bir araştırma, İstanbul Ticaret $\ddot{U} n$ iversitesi Sosyal Bilimler Dergisi, 7(1), 69-87

Kotler, P. (2005). A'dan Z'ye pazarlama. Çev. A. Kalem Bakkal, ISBN: 975-647-59-7, MediaCat Kitapları, İstanbul.

Kozak, N. (2014). Turizm pazarlaması. 5. baskd, ISBN:978-605-5681-85-2, Detay Yayınclik, Ankara

Lauterborn, B., Copyright, (1990). Crain communications, Inc.; New marketing litany; Four $P^{\prime}$ s passe; C-words take over. http://rlauterborn.com/pubs/pdfs/4 Cs.pdf adresinden 30.04.2017 tarihinde erişilmiştir.

Mohammed, R., ve Pervaiz, A. (1995). Using the 7ps as a generic marketing mix: an exploratory survey of UK And European marketing academics. Marketing Intelligence $\mathcal{E}$ Planning, 13(9), 4-15, MCB University Press Limited, 0263-4503. file:///C:/Users/k\%C3\%BCr\%C5\%9Fad/Downloads/Using the 7Ps as a gene ric marketing mix An explor.pdf 01.05.2020 tarihinde erişilmiştir.

Morrison, A., ve Thomas R. (1999). The future of small firms in the hospitality industry. International Journal of Contemporary Hospitality Management, 11(4), 148-154.

Mucuk, İ. (2004). Pazarlama ilkeleri. İstanbul: Türkmen Kitabevi

Prapannetivuth, A., (2015). The marketing mix in small sized hotels: a case of Pattaya, Thailand. World academy of science, engineering and technology. International Journal of Economics and Management Engineering, 9(11). 
Prasanna, K. (2013). Marketing strategies for standalone hotels: with reference to mayur Aaditya Resort, Dharwad, India. Research Journal of Management Sciences. ISSN 2319-1171. 2(5), 14-19.

Quah, W.B., ve Chan, J., K, L. (2008). A study on small and medium-sized accommodation operators in Sabah: Problems and chanllenges. The $7^{\text {th }} \quad$ Asia Pacific Forum For Graduate Students' Research In Tourism June 3-4, 2008, at Universiti Teknologi MARA Malaysia (UiTM), Shah Alam. file:///C:/Users/k\%C3\%BCr\%C5\%9Fad/Downloads/fullpaper- pc\%20(3).pdf adresinden 24.04.2020 tarihinde erişilmiştir.

Rizaoğlu, B. (2004), Turizm pazarlamasl. Ankara: Detay Yayınclık,

Sanb, N.,I,R., Abdulaziz,Y., Samdın, Z., ve Rahım, K.,A. (2013). Comparison of marketing mix dimensions between local and international hotel customers in Malaysia. Int. Journal of Economics and Management, 7(2), 297-313.

Sarker, M., Aimin, W., ve Begum, S. (2012). Investigating the impact of marketing mix elements on tourists 'satisfaction: An empirical study on east lake, European Journal of Business and Management. , 4(7), 273-281. ISSN 2222-1905 (Paper) ISSN 2222-2839 file:///C:/Users/k\%C3\%BCr\%C5\%9Fad/Downloads/Investigating the Impact of_Marketing_Mix_Elements\%20(1).pdf adresinden 01.05.2020 tarihinde erişilmiştir.

Shostack, G., L. (1977). Breaking free from product marketing. Journal of Marketing, 41, 7380

Thwala, K., C., ve Slabbert, E. (2018). The effectiveness of the marketing mix for guesthouses. African Journal of Hospitality, Tourism and Leisure, 7(2), 1-15. ISSN: 2223$814 \mathrm{X}$

Ünalan, M., (2017).Helal gida ürünlerinde pazarlama karması elemanları, GUEJISS, Gümüşhane University Electronic Journal of The Institute of Social Sciences 8(19).

\section{Kaynakça Bilgisi / Citation Information}

Sayın, K. ve Karaman, A. (2020). Küçük otel işletmelerinde, yöneticilerin pazarlama karmasına yönelik tutumları: Bir uygulama. OPUSUluslararası Toplum Araştırmaları Dergisi, 16(32), 4743-4765. DOI: 10.26466/opus.731669 